\title{
Numerical Study of an Ejector as an Expansion Device in Split-type Air Conditioners for Energy Savings
}

\author{
Kasni Sumeru ${ }^{1}$, Shodiya Sulaimon ${ }^{1}$, Farid Nasir Ani ${ }^{1} \&$ Henry Nasution ${ }^{2,3^{*}}$ \\ ${ }^{1}$ Department of Thermodynamics and Fluid Mechanics, \\ Faculty of Mechanical Engineering \\ Universiti Teknologi Malaysia, Skudai, Johor, 81310, Malaysia \\ ${ }^{2}$ Automotive Development Centre, Faculty of Mechanical Engineering \\ Universiti Teknologi Malaysia, Skudai, Johor, 81310, Malaysia \\ ${ }^{3}$ Department of Mechanical Engineering, Faculty of Industrial Technology \\ Universitas Bung Hatta, Jalan Gadjah Mada, Padang, 25143, Indonesia \\ *Email: henry@fkm.utm.my
}

\begin{abstract}
The present study describes a numerical approach for determining both the motive nozzle and constant-area diameters of an ejector as an expansion device, based on the cooling capacity of a split-type air-conditioner using R290 as refrigerant. Previous studies have shown that replacement of HCFC R22 with HC290 (propane) in the air conditioner can improve the coefficient of performance (COP). The purpose of replacing the capillary tube with an ejector as an expansion device in a split-type air conditioner using HC290 is to further improve the COP. In developing the model, conservation laws of mass, momentum and energy equations were applied to each part of the ejector. The numerical results show that the motive nozzle diameter remains constant (1.03 $\mathrm{mm}$ ) under varying condenser temperatures, whereas the diameter of the constant-area decreases as the condenser temperature increases. It was also found that improvement of the COP can reach $32.90 \%$ at a condenser temperature of 55 ${ }^{\circ} \mathrm{C}$. From the results mentioned above, it can be concluded that the use of an ejector can further improve the COP of a split-type air conditioner using HC290 as working fluid.
\end{abstract}

Keywords: COP improvement; ejector; expansion device; propane; split-type air conditioner.

\section{$1 \quad$ Introduction}

Split-type air conditioners are widely used in residential and commercial buildings. It is a well-known fact that air conditioners (AC) consume a very high amount of energy to maintain indoor air temperature. Air-conditioning systems use approximately $50 \%$ of the total energy consumption of a building [1]. As a result, a small improvement in the performance of the system will generate a significant impact on energy savings. There are several ways of improving the performance of the vapor compression refrigeration cycle

Received September $19^{\text {th }}, 2012,1^{\text {st }}$ Revision December $6^{\text {th }}, 2012,2^{\text {nd }}$ Revision January $25^{\text {th }}, 2013$, Accepted for Publication March $19^{\text {th }}, 2013$.

Copyright $\odot 2013$ Published by ITB Journal Publisher, ISSN: 2337-5779, DOI: 10.5614/j.eng.technol.sci.2013.45.2.6 
(VCRC). The use of a heat exchanger for subcooling and superheating is a conventional method. Recently, several researchers have applied an inverter and control method to regulate the motor rotation of the compressor according to the cooling load in the cooled compartment [2-3]. Using an ejector as an expansion device is one of the alternative ways of improving refrigeration cycle performance.

A typical vapor compression refrigeration cycle uses a capillary tube, a thermostatic expansion valve and other throttling devices to reduce refrigerant pressure from condenser to evaporator. Theoretically, the pressure drop in conventional expansion devices is considered an isenthalpic process (constant enthalpy). An isenthalpic process causes a decrease in the evaporator cooling capacity because of energy loss in the throttling process. To recover this energy loss, isentropy (constant entropy) is required in the expansion process. An ejector can be used to generate isentropic conditions in the throttling process. A refrigeration system that uses an ejector as an expansion device, is usually named an ejector-expansion refrigeration cycle (EERC) [4].

The efficiency of an $\mathrm{AC}$ is defined as the ratio of the refrigeration effect on the evaporator to the power consumed by the compressor, and it is expressed as coefficient of performance (COP) or energy efficiency ratio (EER) [5]. Although COP and EER have similar definitions, COP differs from EER with respect to the units used in the numerator and the denominator. COP is dimensionless, whereas EER usually uses Btu/hr for the refrigeration effect and $\mathrm{kW}$ for power consumed by the compressor.

The experiment conducted by Devotta [6] showed that HC290 as a drop-in substitute for HCFC22 in a window air conditioner increases the coefficient of performance by $9.7 \%$. Zhou and Zhang [7] investigated the effect of the length and coil diameter of the capillary tube on the performance of a split-type AC using HCFC22 and HC290. They found that the mass flow rate of the refrigerant tended to increase slightly as the coil diameter of the capillary tube increased. They also found that the energy efficiency ratio (EER) of HC290 could be up to $8.5 \%$ higher than that of HCFC22.

For further COP improvement $\left(\mathrm{COP}_{i m p}\right)$ of a split-type AC using $\mathrm{HC} 290$ as a drop-in substitute for HCFC22, an ejector as an expansion device can be applied. A number of advantages of an ejector as an expansion device have been demonstrated by several researchers. Karhouser [8] was the first to perform a thermodynamics analysis of the vapor compression refrigeration cycle using an ejector as an expansion device. He proposed a one-dimensional model in his 
study. He found that the $\mathrm{COP}_{\text {imp }}$ was up to $21 \%$ over the standard cycle. Liu, et al. [9], Li and Groll [10] and Deng, et al. [11] developed a mathematical model and found that the $\mathrm{COP}_{i m p}$ was between $6-14 \%, 7-18 \%$ and $22 \%$, respectively, over the standard vapor compression refrigeration cycle using $\mathrm{CO}_{2}$ as refrigerant. Takeuchi, et al. [12] reported an increase in $\mathrm{COP}_{i m p}$ of $45-64 \%$ for a vehicle refrigeration system. Disawas and Wongwises [13] and Elbel and Hrnjak [14] carried out experimental investigation on an ejector as an expansion device using $\mathrm{R} 134 \mathrm{a}$ and $\mathrm{CO}_{2}$ respectively, and reported an increment in the COP over the standard cycle. Nehdi, et al. [15] presented a numerical analysis to determine the effect of the geometry of ejectors on system performance using twenty synthetic refrigerants. They found that the $\mathrm{COP}_{i m p}$ over the standard cycle is $22 \%$. A numerical approach using a natural refrigerant in the EERC was performed by Sarkar [16], who reported that the maximum $\mathrm{COP}_{\text {imp }}$ for isobutene, propane and ammonia is $21.6 \%, 17.9 \%$ and $11.9 \%$ respectively. Bilir and Ersoy [17] performed a computational analysis of the performance improvement of the ejector expansion cycle over the standard cycle. In their computational analysis they proposed a method similar to that of Kornhauser [8]. They found that using an R134a refrigerant, the COP improvement of the expansion cycle over the standard cycle is about 10.1 to $22.34 \%$.

Based on a survey of the literature, we have not found any study on the EERC that investigated the determination of the diameters of the motive nozzle and the constant-area based on the cooling capacity of the air conditioner. The objective of the present study is to obtain the diameters of the motive nozzle and the constant-area of the ejector in relation to COP improvement in the split-type air conditioner using R290 (propane) as working fluid.

\section{System Description and Thermodynamics Modeling}

\subsection{An Ejector as an Expansion Device}

The idea of a two-phase ejector as an expansion device is not new. In 1931, Gay patented the use of an ejector to minimize throttling losses in the expansion device in a vapor compression refrigeration cycle (VCRC). In 1966, Kemper, et al. [18] modified Gay's patent by using a pump and a heater to increase the pressure and temperature of the liquid stream before it enters the motive nozzle. In 1972, Newton [19-20] proposed two patents to improve the previous patent by Kemper.

Figure 1 depicts a schematic diagram of the standard cycle and an ejector as an expansion device. A capillary tube or expansion valve is used as an expansion 
device in the standard cycle, whereas an ejector is used as an expansion device in the EERC.

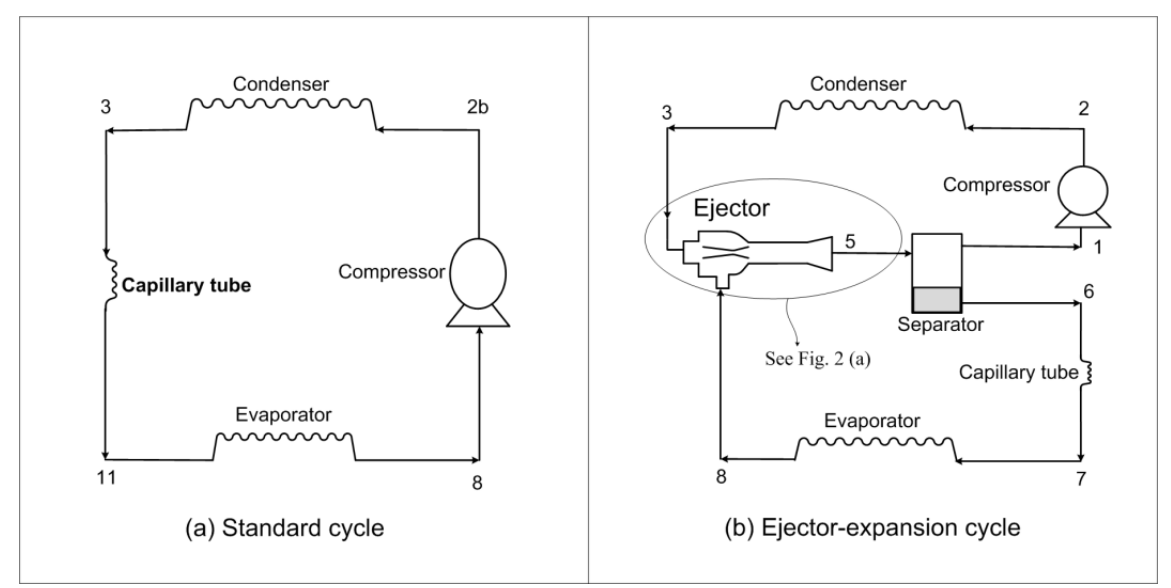

Figure 1 Schematic diagram of the vapor compression refrigeration cycle: (a) standard cycle; (b) EERC.

Figure 2(a) illustrates the refrigerant flow, pressure and velocity profile inside the ejector. Figure 2(b) shows a $\mathrm{Ph}$ diagram of the standard cycle and the EERC. The isenthalpic throttling process takes place from point 3 to 11, while the isentropic throttling process takes place from point 3 to 4 . Refrigerant flow in the $\mathrm{Ph}$ diagram of the standard cycle is point $8,2 \mathrm{~b}, 3,11$ and 8 . There are two flows in the EERC: primary flow and secondary flow. The primary flow is circulated by a compressor through the condenser, ejector and separator (point $1,2,3,4,10,5$ and 1 ), whereas the secondary flow circulates in the capillary tube, evaporator, ejector and separator (point 6, 7, 8, 9, 10, 5 and 6). The primary and secondary flows mix at the constant-area and diffuser (point 10 and 5). The sudden change in pressure and velocity of the refrigerant from point 9 to 10 is attributed to normal shock, induced downstream of the constant area mixing section. This shock causes a compression effect and thus results in a sudden drop in the refrigerant flow speed [21]. As shown in Figure 2(b), the pressure at point 1 is higher than that of the suction pressure in the standard cycle (point 8). This means that the compressor work of the ejector expansion cycle is lower than that of the standard cycle. Based on Figure 2(b), the COP of the standard refrigeration cycle is calculated as,

$$
C O P_{\text {std }}=\frac{Q_{e}}{W_{\text {comp }}} \cdot \eta_{\text {comp }}=\frac{\dot{m}_{e}\left(h_{8}-h_{11}\right)}{\dot{m}_{\text {comp }}\left(h_{2 b}-h_{8}\right)} \cdot \eta_{\text {comp }}
$$




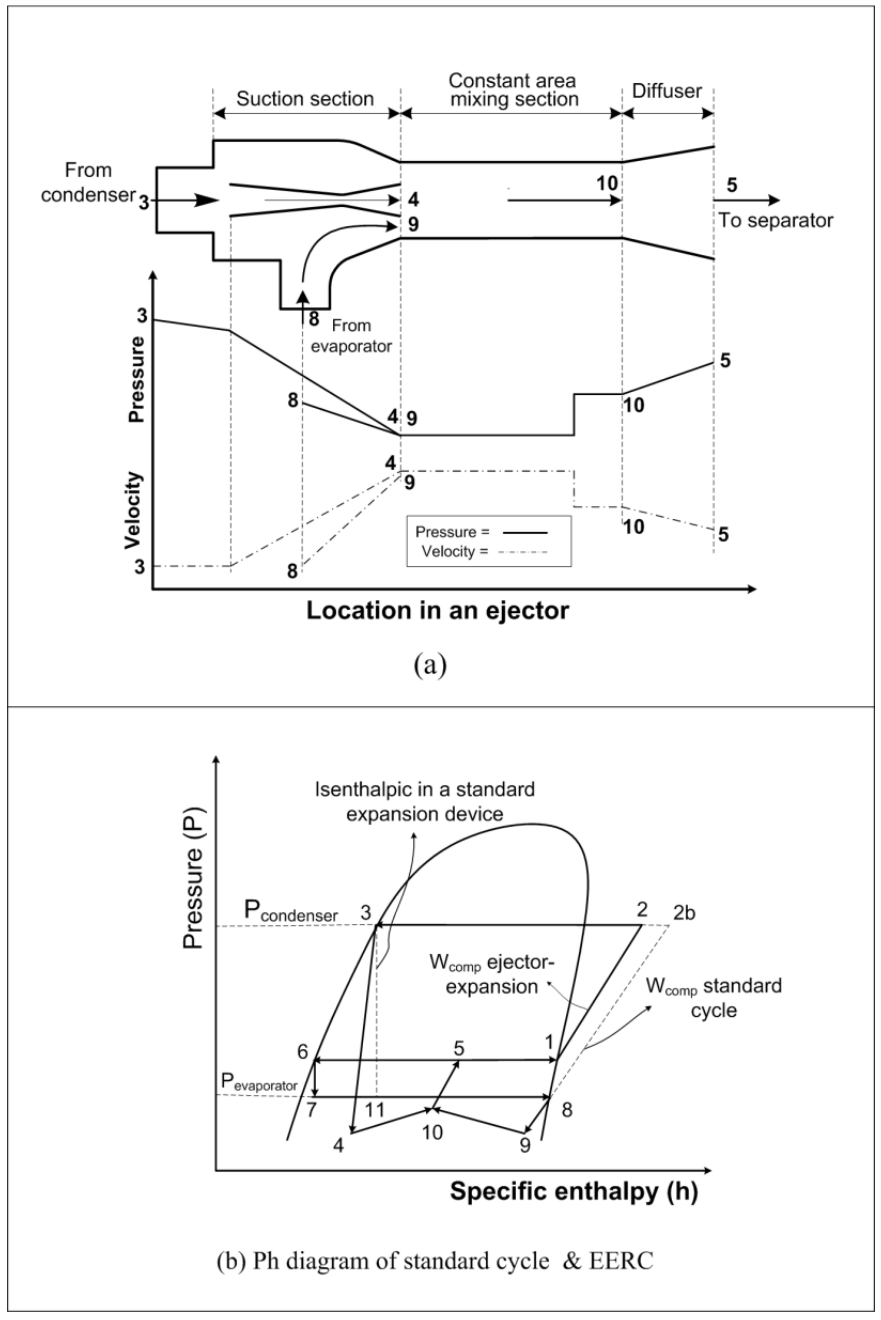

Figure 2 (a) Pressure and velocity profile in the ejector; (b) $\mathrm{Ph}$ diagram of the EERC and standard cycle.

since $\dot{m}_{e}=\dot{m}_{\text {comp }}$, Eq. (1) becomes,

$$
C O P_{s t d}=\frac{\left(h_{8}-h_{11}\right)}{\left(h_{2 b}-h_{8}\right)} \cdot \eta_{c o m p}
$$

where $\eta_{\text {comp }}$ is the isentropic efficiency of the compressor, which is calculated by an empirical relation in Brunin, et al. [22] as, 


$$
\eta_{\text {comp }}=0.874-0.01345 \frac{P_{\text {disc }}}{P_{\text {suct }}}
$$

Furthermore, the COP of the EERC is,

$$
C O P_{e j}=\frac{Q_{e}}{W_{\text {comp }}} \cdot \eta_{\text {comp }}=\frac{\dot{m}_{e}}{\dot{m}_{\text {comp }}} \cdot \frac{\left(h_{8}-h_{7}\right)}{\left(h_{2}-h_{1}\right)} \cdot \eta_{c o m p}
$$

The COP improvement of the EERC over the standard cycle can be calculated by,

$$
C O P_{i m p}=\frac{\left(C O P_{e j}-C O P_{s t d}\right)}{C O P_{s t d}}
$$

The EERC is characterized using two parameters, the entrainment ratio $(\omega)$ and pressure lifting ratio $\left(P_{l i f t}\right)$. The definitions of the two parameters are:

$$
\begin{aligned}
& \omega=\frac{\dot{m}_{e}}{\dot{m}_{c}} \\
& P_{\text {lift }}=\frac{P_{\text {dif }, \text { out }}}{P_{e, \text { out }}}=\frac{P_{1}}{P_{8}}
\end{aligned}
$$

Both quantities should be as high as possible to obtain optimum $\mathrm{COP}_{\text {imp }}$. A high ejector pressure lifting ratio decreases the compression ratio of the compressor. Increasing the mass entrainment ratio will reduce the compressor mass flow rate for a given cooling capacity.

\subsection{Thermodynamics Modeling and Calculation Algorithm}

In developing the thermodynamic model, the governing equations that are applied to each part of the ejector are: conservation of mass, momentum and energy in Eqs. (8), (9) and (10), respectively.

$$
\begin{aligned}
& \sum \rho_{i} u_{i} a_{i}=\sum \rho_{o} u_{o} a_{o} \\
& P_{i} a_{i}+\sum \dot{m}_{i} u_{i}=P_{o} a_{o}+\sum \dot{m}_{o} u_{o} \\
& \sum \dot{m}_{i}\left(h_{i}+\frac{u_{i}^{2}}{2}\right)=\sum \dot{m}_{o}\left(h_{o}+\frac{u_{o}^{2}}{2}\right)
\end{aligned}
$$

To apply the equations above in the calculation of each part of the ejector, the following assumptions were made: 
1. There is no heat transfer except in the evaporator and condenser.

2. Properties and velocities are constant over the cross section (onedimensional).

3. The refrigerant condition is in thermodynamic quasi-equilibrium.

4. There is no pressure drop along the evaporator and condenser.

5. There is no wall friction.

6. The refrigerant conditions at the outlet of the evaporator and condenser are saturated.

7. Deviation from adiabatic reversible processes for each section of the ejector is calculated by efficiencies.

Based on the manipulation of Eqs. (8)-(10) and referring to studies performed by Nehdi, et al. [15] and Sarkar [16], the thermodynamics modeling produces Eqs. (11)-(20), as shown in the flowchart depicted in Figure 3. This flowchart was used to determine the diameter of the motive nozzle $\left(\mathrm{d}_{4}\right)$ and the constantarea of the ejector $\left(\mathrm{d}_{10}\right)$. Using flowchart (Figure 3 ) and properties of the refrigerant, several parameters, such as the diameters of the motive nozzle and the constant-area, $P_{l i f t}, \mathrm{COP}_{e j}$ and $\mathrm{COP}_{i m p}$, can be calculated.

\section{$3 \quad$ Results and Discussion}

To calculate the diameters of the motive nozzle and the constant-area, the mass flow rate of the standard refrigeration cycle must be known. The value of the mass flow rate represents the cooling capacity of the air conditioner. In the present study, a split-type air conditioner with HC290 (propane) as working fluid, a cooling capacity of $2.4 \mathrm{~kW}$ and a mass flow rate of $27.48 \mathrm{~kg} / \mathrm{h}$, was used to calculate the diameters of the motive nozzle and the constant-area. This data was taken based on the experimental results of Zhou and Zhang [7]. To start the iteration using the flowchart in Figure 3, the values of nozzle and diffuser efficiencies was chosen as 0.9 and 0.8 , respectively [23].

\subsection{Effect of Condenser Temperature on Geometric Parameters}

In the application, a split-type AC can be installed in geographical areas with moderate or high outdoor air temperatures. For this reason, the motive nozzle and constant-area diameters of the ejector must be designed according to these conditions. The dimension of each section of the ejector is crucial in improving the COP. The diameter of the motive nozzle is calculated by using Eq. (13), while the diameter of the constant-area is iterated by the flowchart depicted in Figure 3. The iteration results are shown in Figure 4. It shows that the diameter of the motive nozzle is constant, at $1.03 \mathrm{~mm}$, except at a condenser temperature of $55^{\circ} \mathrm{C}(0.98 \mathrm{~mm})$. The diameters of the motive nozzle based on the numerical 


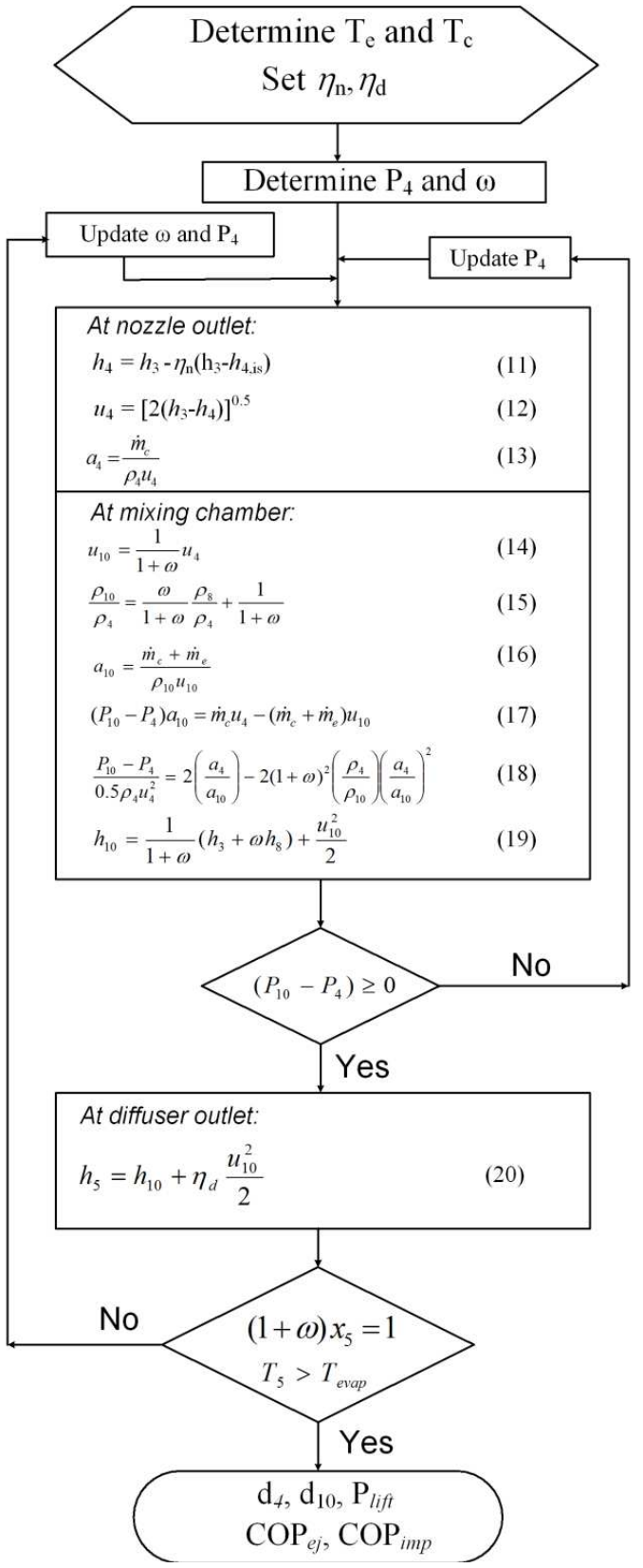

Figure 3 Flow chart of the calculation algorithm of motive nozzle and constantarea diameters. 
results is similar to those used in the experiment of Caiwongsa and Wongwises [24]. They tested three different motive nozzle diameters $(0.8,0.9$ and $1.0 \mathrm{~mm})$, using R134a. The motive nozzle with a diameter of $1.0 \mathrm{~mm}$ yielded a higher mass flow rate in the condenser than the other nozzles, while the smallest diameter $(0.8 \mathrm{~mm})$ yielded a lower mass flow rate in the condenser, producing the highest $\mathrm{COP}_{\text {imp. }}$. There is a slight difference between the numerical approach and the experimental data. This distinction is caused, among other things, by differences in the working fluid and cooling capacity.

Figure 4 shows that the constant-area diameter decreases with an increase in condenser temperature. For example, when the diameter of the constant-area is 2.14, 2.12 and $2.01 \mathrm{~mm}$, the condenser temperatures are 45,50 , and $55^{\circ} \mathrm{C}$, respectively. The main geometric parameter of an ejector is area ratio (AR), which is defined as the ratio between the cross-sectional area of the constantarea to the motive nozzle $\left(a_{10} / a_{4}\right)$. Figure 4 shows that the area ratio decreases as the condenser temperature increases. With similar results in the present study, Sarkar [20] reported that the ejector AR decreased with an increase in the condenser temperature. However, his numerical model did not investigate either the motive nozzle or the constant-area, which has a more pronounced decrement. The experimental study by Disawas and Wongwises [13] and Elbel and Hrnjak [14] only investigated the effect of the nozzle diameter on the system. The numerical results of the present study show that the decrement of the area ratio of the ejector is more influenced by the constant-area diameter than the motive nozzle diameter, as shown in Figure 4.

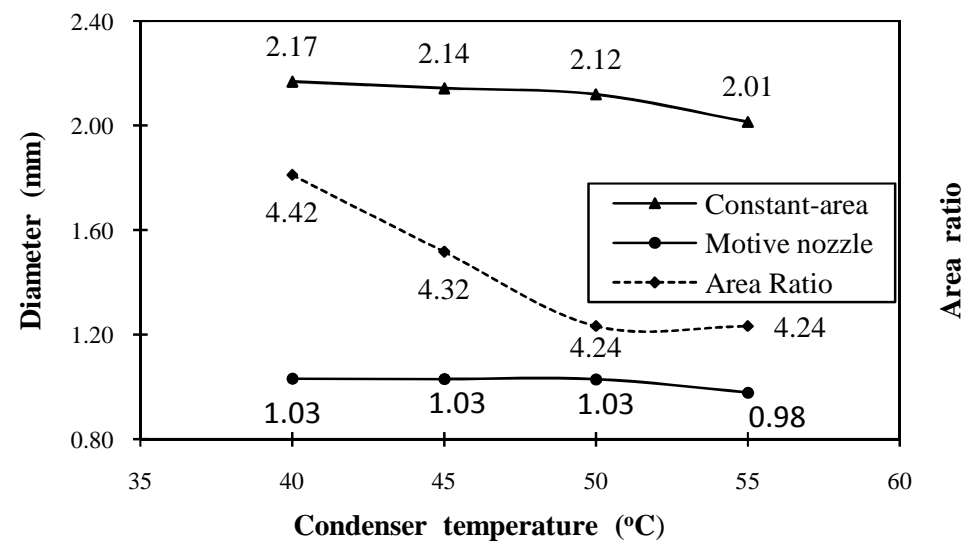

Figure 4 Variation of motive nozzle and constant-area diameters, and area ratio of ejector versus condenser temperature $\left(\mathrm{T}_{\mathrm{e}}=5^{\circ} \mathrm{C}, \eta_{\mathrm{n}}=0.9\right.$ and $\left.\eta_{\mathrm{d}}=0.8\right)$. 


\subsection{Effect of Condenser Temperature on COP Improvement}

It is well known that the COP of a standard refrigeration cycle decreases as the condenser temperature increases, as shown in Figure 5. The effect of COP reduction due to condenser temperature increment is greater in the standard cycle than in the EERC. As a result, the $\mathrm{COP}_{i m p}$ of the EERC is better for higher condenser temperatures. For example, as shown in Figure 5, the $\mathrm{COP}_{i m p}$ is $23.46 \%$ at $\mathrm{T}_{\mathrm{c}}=50{ }^{\circ} \mathrm{C}$ and becomes $31.97 \%$ at $\mathrm{T}_{\mathrm{c}}=55^{\circ} \mathrm{C}$. This means that there was a reduction in power consumption (energy savings) of the split-type AC due to the use of an ejector as an expansion device.



Figure 5 Variation of $\mathrm{COP}$ and $\mathrm{COP}$ improvement versus condenser temperature $\left(\mathrm{T}_{\mathrm{e}}=5^{\circ} \mathrm{C}, \eta_{\mathrm{n}}=0.9\right.$ and $\left.\eta_{\mathrm{d}}=0.8\right)$.

Figure 5 shows that the $\mathrm{COP}_{\text {imp }}$ increases relatively significantly at condenser temperatures above $40{ }^{\circ} \mathrm{C}$. Indeed, the improvement in the $\mathrm{COP}$ can reach $31.97 \%$ at a condenser temperature of $55^{\circ} \mathrm{C}$. These results indicate that the use of an ejector as an expansion device is effective for geographical areas that have high outdoor air temperatures.

\subsection{Effect of Condenser Temperature on $\mathbf{P}_{\text {lift }}$}

Theoretically, the $\mathrm{P}_{\text {lift }}$ value should be as high as possible in order to obtain maximum $\mathrm{COP}_{\text {imp }}$. However, the condition of $(1+\omega) \cdot \mathrm{x}_{5}=1$ must be fulfilled for a realistic flow. As depicted in the $\mathrm{Ph}$ diagram in Figure 2(b), the compressor work decreases when $\mathrm{P}_{1}$ increases, due to the enthalpy difference $\left(\mathrm{h}_{2}-\mathrm{h}_{1}\right)$ being reduced. $\mathrm{P}_{\text {lift }}$ is calculated by Eq. (7), and $\mathrm{P}_{8}$ in the present study is constant, i.e. $551.12 \mathrm{kPa}$. The iteration results obtained for various $\mathrm{P}_{1}$ and $\mathrm{T}_{5}$ with different condenser temperatures are shown in Table 1. 
Table 1 Variation $\mathrm{P}_{5}$ and $\mathrm{T}_{5}$ versus the condenser temperature, where $\mathrm{T}_{\mathrm{e}}=5$ ${ }^{\circ} \mathrm{C}, \eta_{\mathrm{n}}=0.9$ and $\eta_{\mathrm{d}}=0.8$.

\begin{tabular}{cccccc}
\hline $\mathbf{T}_{\mathbf{c}}\left({ }^{\circ} \mathbf{C}\right)$ & $\mathbf{3 5}$ & $\mathbf{4 0}$ & $\mathbf{4 5}$ & $\mathbf{5 0}$ & $\mathbf{5 5}$ \\
\hline $\mathrm{P}_{5}(\mathrm{kPa})$ & 573.18 & 582.34 & 595.19 & 608.29 & 623.53 \\
$\mathrm{~T}_{5}\left({ }^{\circ} \mathrm{C}\right)$ & 6.34 & 6.89 & 7.64 & 8.40 & 9.27 \\
\hline
\end{tabular}

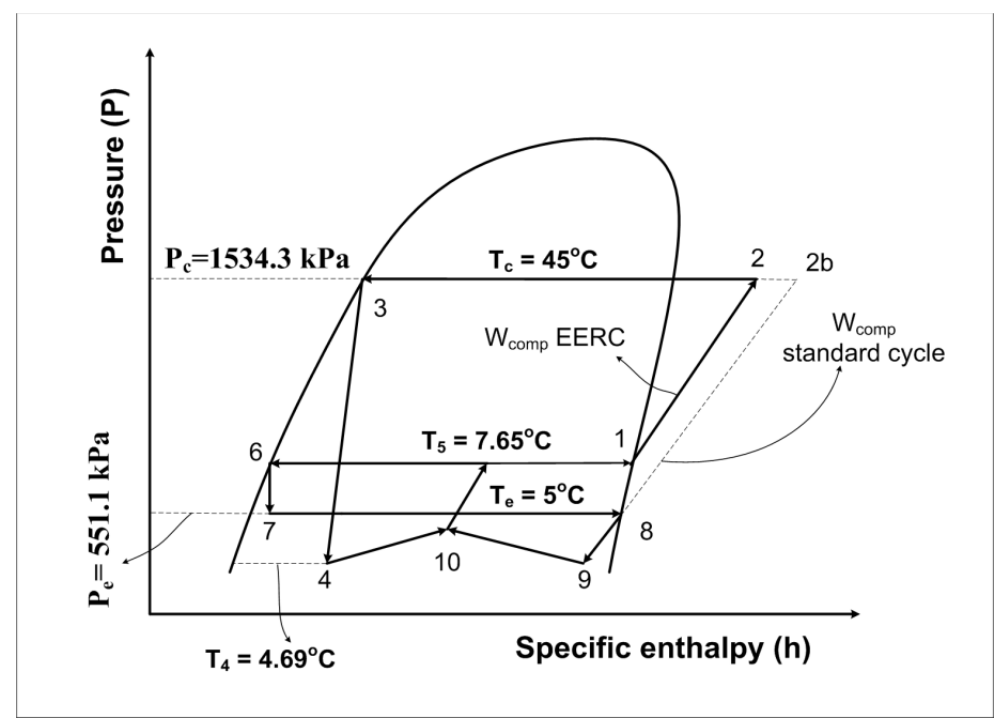

Figure $6 \mathrm{Ph}$ diagram of the $\operatorname{EERC}\left(\mathrm{T}_{\mathrm{e}}=5^{\circ} \mathrm{C}, \mathrm{T}_{\mathrm{c}}=45^{\circ} \mathrm{C}, \eta_{\mathrm{n}}=0.9\right.$ and $\left.\eta_{\mathrm{d}}=0.8\right)$.

Figure 6 shows details of the EERC with $\mathrm{T}_{\mathrm{c}}=45^{\circ} \mathrm{C}, \mathrm{T}_{\mathrm{e}}=5^{\circ} \mathrm{C}$ in a $\mathrm{Ph}$ diagram. The temperature and pressure data were obtained by iteration using the flowchart in Figure 3 and the data from Table 1. A detailed drawing of the EERC in a $\mathrm{Ph}$ diagram is scarce in the literature.

\section{Conclusions}

It is a known fact that HC290 as drop-in substitute for HCFC22 can increase the COP, and our numerical results have shown that replacement of the capillary tube with an ejector as an expansion device in split-type air conditioners using HC290 as a working fluid can further improve the COP. The improvement in the COP showed a significant increase with an increase in condenser temperature. This indicates that the use of an ejector as an expansion device in split-type air conditioners is recommended for geographical areas with high outdoor air temperatures. The results of this study also show that the decrement 
of the area ratio of the ejector is more influenced by the constant-area diameter than by the motive nozzle diameter.

\section{Acknowledgements}

The authors wish to acknowledge the support provided by Universiti Teknologi Malaysia: FRGS Fund No.78686, Ministry of Higher Education (MOHE) Malaysia.

\section{Nomenclature}

$\begin{array}{ll}a & \text { cross-sectional area }\left(\mathrm{m}^{2}\right) \\ \mathrm{AR} & \text { area ratio } \\ \mathrm{COP} & \text { coefficient of performance } \\ d & \text { diameter }(\mathrm{m}) \\ \mathrm{h} & \text { specific enthalpy }(\mathrm{kJ} / \mathrm{kg}) \\ \dot{m} & \text { mass flow rate of fluid }(\mathrm{kg} / \mathrm{s}) \\ \mathrm{P} & \text { pressure }(\mathrm{kPa}) \\ \mathrm{P}_{l i f t} & \text { pressure lift ratio } \\ \mathrm{Q} & \text { cooling capacity }(\mathrm{kJ} / \mathrm{kg}) \\ \mathrm{s} & \text { specific entropy }(\mathrm{kJ} / \mathrm{kg} . \mathrm{K}) \\ u & \text { fluid velocity }(\mathrm{m} / \mathrm{s}) \\ \mathrm{W} & \text { compressor work }(\mathrm{kJ} / \mathrm{kg}) \\ \eta_{d} & \text { diffuser efficiency } \\ \eta_{n} & \text { nozzle efficiency } \\ \rho & \text { fluid density }\left(\mathrm{kg} / \mathrm{m}^{3}\right) \\ \omega & \text { entrainment ratio } \\ x & \text { vapor quality }\end{array}$

\begin{tabular}{ll}
\multicolumn{2}{l}{ Subscripts } \\
$c$ & condenser \\
comp & compressor \\
disc & discharge of \\
& compressor \\
dif & diffuser \\
$e$ & evaporator \\
$e j$ & ejector \\
$i$ & inlet \\
imp & improvement \\
$n$ & nozzle \\
$o$ & outlet \\
std & standard \\
suct & suction of \\
& compressor
\end{tabular}

\section{References}

[1] Lombard, L.P., Ortiz, J. \& Pout, C., A Review on Buildings Energy Consumption Information, Energy and Buildings, 40(3), pp. 394-398, 2008.

[2] Cecchinato, L., Part Load Efficiency of Packaged Air-Cooled Water Chillers with Inverter Driven Scroll Compressors, Energy Conversion and Management, 51(7), pp. 1500-1509, 2010.

[3] Nasution, H. \& Hasan, M.N.W., Potential Electricity Savings by Variable Speed Control of Compressor for Air Conditioning Systems, Clean Technologies and Environmental Policy, 8(2), pp. 105-111, 2006.

[4] Sumeru, K., Ani, F.N. \& Nasution, H., A Review on Two-Phase Ejector as An Expansion Device in Vapor Compression Refrigeration Cycle, Renewable and Sustanaible Energy Reviews, 16(7), pp. 4927-4937, 2012. 
[5] Ananthanarayanan, P.N., Basic Refrigeration and Air Conditioning, Third edition, McGraw-Hill Publishing Company Limited, New Delhi, pp. 467-468, 2006.

[6] Devotta, S., Padalkar, A.S. \& Sane, N.K., Performance Assessment of HC-290 as A Drop-In Substitute To HCFC-22 In A Window Air Conditioner, International Journal of Refrigeration 28(4), pp. 594-604, 2005.

[7] Zhou, G., Zhang, Y., Performance of A Split-Type Air Conditioner Matched with Coiled Adiabatic Capillary Tubes Using HCFC22 and HC290, Applied Energy, 87(5), pp. 1522-1528, 2010.

[8] Kornhauser, A.A., The Use of An Ejector As A Refrigerant Expander, In: Proceeding of the USN/IIR-Purdue Refrigeration Conference, West Lafayette, IN, USA, pp. 10-19, 1990.

[9] Liu, J.P., Chen, J.P., \& Chen, Z.J., Thermodynamic Analysis on TransCritical R744 Vapor Compression/Ejection Hybrid Refrigeration Cycle, In: Proceeding of the Fifth IIR Gustav Lorentzen Conference on Natural Working Fluid. Guangzhou, China, pp.184-188, 2002.

[10] Li, D. \& Groll, E.A., Transcritical $\mathrm{CO}_{2}$ Refrigeration Cycle with EjectorExpansion Device, International Journal of Refrigeration, 28(5), pp.766773, 2005.

[11] Deng, J.Q, Jiang, P.X., Lu, T. \& Lu, W., Particular Characteristics of Transcritical $\mathrm{CO}_{2}$ Refrigeration Cycle with An Ejector, Applied Thermal Engineering, 27(2-3), pp. 381-388, 2007.

[12] Takeuchi, H., Nishijima, H. \& Ikemoto, T., World's First High Efficiency Refrigeration Cycle with Two-Phase Ejector: "Ejector Cycle", In: SAE World Conggres, Detroit, MI, USA, Paper 2004-01-0916, 2004.

[13] Disawas, S. \& Wongwises, S., Experimental Investigation on The Performance of The Refrigeration Cycle Using A Two-Phase Ejector as An Expansion Device, International Journal of Refrigeration, 27(6), pp. 587-594, 2004.

[14] Elbel, S. \& Hrnjak, P., Experimental Validation of A Prototype Ejector Designed to Reduce Throttling Losses Encountered in Transcritical R744 System Operation, International Journal of Refrigeration, 31(3), pp. 411422, 2008.

[15] Nehdi, E., Kairouani, L. \& Bouzaina, M, Performance Analysis of The Vapour Compression Cycle Using Ejector as An Expander, International Journal of Energy Research, 31(4), pp. 364-375, 2007.

[16] Sarkar, J., Geometric Parameter Optimization of Ejector-Expansion Refrigeration Cycle with Natural Refrigerants, International Journal of Energy Research, 34(1), pp. 84-94, 2010.

[17] Bilir, N. \& Ersoy, H.K., Performance Improvement of The Vapour Compression Refrigeration Cycle by A Two-Phase Constant-Area 
Ejector, International Journal of Energy Research, 33(5), pp. 469-480, 2009.

[18] Kemper, G.A., Harper, G.F. \& Brown, G.A., Multiple Phase Ejector Refrigeration System, US Patent Patent No. 3, 277, 660, 1966.

[19] Newton, A.B., Capacity Control for Multiphase-Phase Ejector Refrigeration System, US Patent No. 3, 670, 519, 1972a.

[20] Newton, A.B., Control for Multiphase-Phase Ejector Refrigeration System, US Patent No. 3, 701, 264, 1972b.

[21] Chunnanond, K. \& Aphornratana, S., Ejectors: Applications in Refrigeration Technology, Renewable \& Sustainable Energy Reviews, 8 , pp.129-155, 2004.

[22] Brunin, O., Feidt, M. \& Hivet, B., Comparison of The Working Domains of Some Compression Heat Pumps and A Compression-Absorption Heat Pump, International Journal of Refrigeration, 20(5), pp. 308-318, 1997.

[23] Ersoy, H.K. \& Bilir, N., The Influence of Ejector Component Efficiencies on Performance of Ejector Expander Refrigeration Cycle and Exergy Analysis, International Journal of Exergy, 7(4), pp. 425-438, 2010.

[24] Chaiwongsa, P. \& Wongwises, S., Effect of Throat Diameters of The Ejector on The Performance of The Refrigeration Cycle Using A TwoPhase Ejector as An Expansion Device, International Journal of Refrigeration, 30(4), 601-608, 2007. 